\title{
Cashew Nut is Reshaping the Rural Landscape of the Seguela Sub-Prefecture (Northwestern Côte d'Ivoire)
}

\author{
Issouf Bamba*, Herman Madou Guemi, Yao Sadaiou Sabas Barima, Yao Charles Sangne \\ Department of Environment Université Jean Lorougnon Guédé, Daloa, Côte d'Ivoire \\ Email address: \\ bambisso@yahoo.fr(I. Bamba),hermannguemi@gmail.com(H. M. Guemi), byssabas@yahoo.fr(Y. S. S. Barima), \\ y_sangne@yahoo.fr(Y.C. Sangne) \\ ${ }^{*}$ Corresponding author
}

\section{To cite this article:}

Issouf Bamba, Herman Madou Guemi, Yao Sadaiou Sabas Barima, Yao Charles Sangne. Cashew Nut is Reshaping the Rural Landscape of the Seguela Sub-Prefecture (Northwestern Côte d'Ivoire). International Journal of Natural Resource Ecology and Management.

Vol. 4, No. 1, 2019, pp. 22-28. doi: 10.11648/j.ijnrem.20190401.14

Received: February 8, 2019; Accepted: March 22, 2019; Published: April 13, 2019

\begin{abstract}
Over the last decade, cashew tree cultivation has grown significantly in the sub-prefecture of Séguéla (northwestern Côte d'Ivoire) to the point where it has become the main cash crop. The objective of this study is to analyze the spatio-temporal dynamics of the landscape of this region under the impetus of the expansion of cashew cultivation. To achieve this goal, land use maps were generated from the digital processing of four Landsat satellite images (2001, 2006, 2013 and 2018). Subsequently, the evolution rates and spatial structure indices of the plantation were then used to analyze its spatial dynamics in the district's landscape. The study shows that between 2001 and 2018, the composition and structure of the landscape of the Séguéla sub-prefecture experienced significant changes with regard to cashew nut cultivation. At the spatial level, the creation process for new, larger plantations has been identified. In fact, a very limited number of cashew orchards in 2001 with only 83 plantations increased to 1290 in 2018 . The total area of cashew tree plantations has also increased by more than $7000 \%$ to $4,678.5$ ha in 2018 . Such gain in the cashew nut sector is at the expense of food crops, raising concerns about food insecurity and land conflicts in this rural area in the long term.
\end{abstract}

Keywords: Landscape Dynamics, Séguéla Sub-prefecture, Remote Sensing, Land Use, Cashew Nut, Crop Expansion

\section{Introduction}

Originally from South America, Cashew (Anacardium occidentale L.) introduced in the 1950s in West Africa is experiencing significant growth in many countries [1]. Cashew nut cultivation plays an undeniable role in improving people's incomes in west Africa [2]. In Côte d'Ivoire, cashew nuts are mainly produced in the northern Sudanese area where they were introduced in the 1960s to fight against desertification and soil erosion [1,3]. In recent years, attractive prices have led to the expansion of this crop, which has become the main source of income for producers in the savannah regions of northern and central Côte d'Ivoire [4]. Today, Côte d'Ivoire is the leading African producer, the world's largest exporter of cashew nuts and the second largest producer in the world, with an estimated production of $550,000 \mathrm{~T}$ in 2014. Most of the studies conducted on cashew nut cultivation have been aimed mainly at improving the agro-economic performance of farms and the economic and social impact on cashew nuts-producing populations [5].

However, the expansion of this culture raises serious concerns about soil resources and water quality and the landscape transformation in entails [6]. Indeed, the so-called perennial crops, which monopolize the space for several decades, are reputed to be large consumers of land in rural areas [5] often to the disadvantage of other crops such as food crops. As a result, the risk of food insecurity and land conflicts increases [8-9]. Moreover, its known that perennial crops also impact negatively ecosystems [5]. The present study carried out in the sub-prefecture of Séguéla in northwest Côte d'Ivoire assumes that the expansion of cashew nut cultivation has led to changes in the structure and spatial configuration of the landscape. Through cartography and landscape ecology techniques, the study aims to analyze changes in the spatial structure of the landscape of the Séguéla sub-prefecture between 2001 and 2018 in response 
to the expansion of cashew nut cultivation.

\section{Material and Methods}

\subsection{Study Area}

The Séguéla sub-prefecture is in northwestern Côte d'Ivoire, within the forest-savannah contact zone dominated by the savannah [10]. In this area, the climate favorable to cashew nut cultivation is characterized by two seasons; an 8month dry season from November to June and a 4-month rainy season from July to October with an average temperature value of $28^{\circ} \mathrm{C}$ [11].
Covering an area of $842.15 \mathrm{sqkm}$ (square kilometers) the sub-prefecture (Figure 1) has an estimated population of 63,774 inhabitants. The density of population is about 76 inhabitants/sqkm more concentrated in the city of Séguéla, the capital of the district. Agricultural activity is the main source of income for the majority of the population. In 2012, cashew nuts were already the predominant flagship product of the farmers in the district [12]. The district's contribution to cashew nut production has positioned the region among the leading cashew nut producing regions with more than $25,000 \mathrm{~T}$ in 2012 [13].

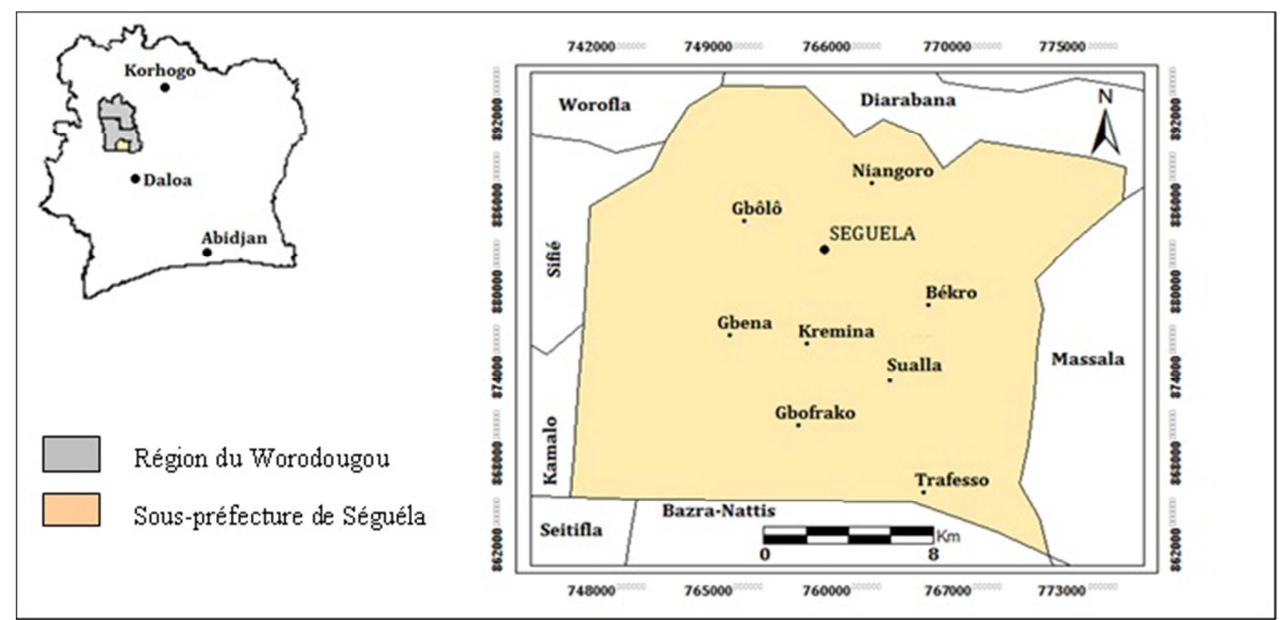

Figure 1. Localisation of the Séguéla sub-prefecture in the Worodougou region. It is in the northwest of Côte d'Ivoire, about $475 \mathrm{~km}$ from the economic capital Abidjan.

\subsection{Data and Methods}

\subsubsection{Spatial and Cartographic Data}

The spatial data used consist of 4 remote sensing images from 2001, 2006, 2013 and 2018, all taken during the dry season (Table 1). These images were acquired for free by downloading from the Global Land Cover Facility (GLCF) website. The cartographic data concern the files containing the tables and shapefiles of the road networks, localities and the administrative breakdown of Côte d'Ivoire obtained from the Centre de cartographie et de télédétection (CCT) of the Bureau National d'Etude Technique et de Développement (BNETD).

Table 1. Characteristics of the satellite images (Scene reference (path/Row): 198/054).

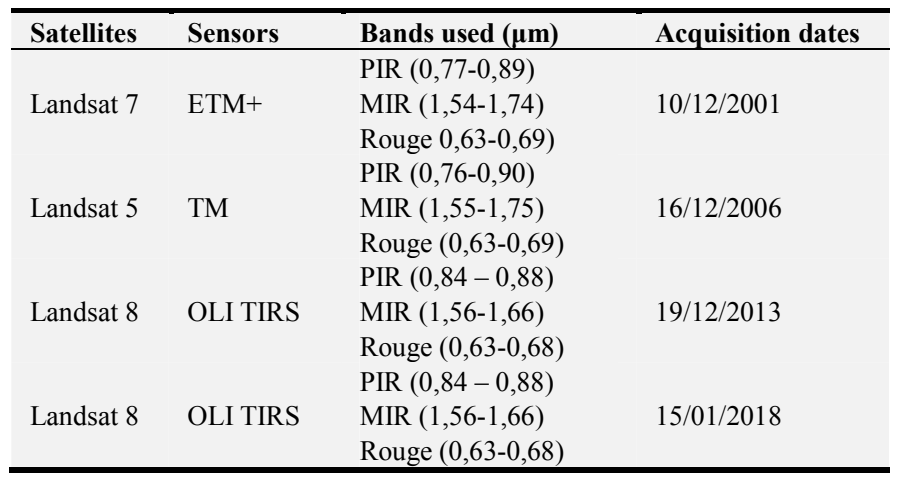

\subsubsection{Methods}

Satellite image processing required the use of ENVI 4.7 software. After classification, the maps were produced using ArcGIS 10.2 software.

i Image processing and map production

After their acquisition, the images (Path 198 and Row 054) were adjusted geometrically to make them stackable in order to facilitate comparison in terms of dynamics. Then, the study area was extracted from the image scenes by using the vector files of the Séguéla sub-prefecture contour as a training area.

ii Colour composition and image classification

Colour compositions were produced by combining channels 4 for near-infrared [0.75-0.90 $\mu \mathrm{m}], 5$ for medium infrared [1.55-1.75 $\mu \mathrm{m}]$ and 3 for red [0.63-0.69 $\mu \mathrm{m}]$ with the colour order red, green, blue for Landsat ETM+ (2001) and TM (2006) images. For the Landsat OLI images (2013 and 2018), the combinations involved near-infrared bands 5 [0.85-0.88 $\mu \mathrm{m}]$ in red, medium infrared bands $6[1.55-1.75 \mu \mathrm{m}]$ in green and red bands 4 [0.64-0.67 $\mu \mathrm{m}]$ in blue. Following the colour composition, a visual interpretation and identification of the areas to be checked in the field followed. The identification of cashew tree orchards was the main purpose of the field visit. After field visits, a supervised classification with the "maximum likelihood" algorithm [14] was performed to produce files to study the dynamics of composition and structure of cashew orchards in the study area. 
iii Classification performance and mapping

The performance of the classifications was based on four matrices of confusion comparing the classes obtained following the baseline data collected during the field visits. Thus, for each classification, widely used measures such as overall accuracy and kappa coefficient have been calculated [15]. The classified images were filtered from the Spatial Analysis Tools (Majority filter) with a window size of $3 \times 3$ pixels. The principle of filtering consists in modifying the numerical value of each pixel according to the values of the neighboring pixels [16]. The processing of satellite images was finalized by the restitution of thematic maps. The classification process made it possible to select three land use classes in order to focus on cashew nut plantations. The data from the maps made it possible to generate descriptive statistics on the areas of the different land use classes for each of the four dates defined. The comparison of the maps and the corresponding statistical series revealed changes in cashew nut culture in 2001, 2006, 2013 and 2018.

iv Highlighting changes

The spatial structure of the landscape was characterized by indices using area and number of patches in each of the land cover classes. Temporal trends in land use class areas were used to determine the change that occurred between two periods. The rate of change (Te) was calculated according to equation (1).

$$
T_{e}=\frac{a_{t 1}-a_{t 0}}{a_{t 0}} \times 100
$$

For the cashew nut class, further measurements were also made. These include the average area of cashew plantations, the perimeter of cashew plantations and the dominance of the largest patch which represents the proportion occupied in the landscape by the area of the largest cashew plantations. The higher the value of dominance $(100 \%)$, then only one large patch dominates the landscape and this value decreases as plantation sizes become equivalent [17].

The spatial transformation process quantifies land use changes between two dates t0 and 11 [18]. To do this, the number of patches, area and perimeter of each class must be considered. The decision tree (Figure 2) proposed by reference [18] was used to identify the spatial transformation process for the cashew nut class.

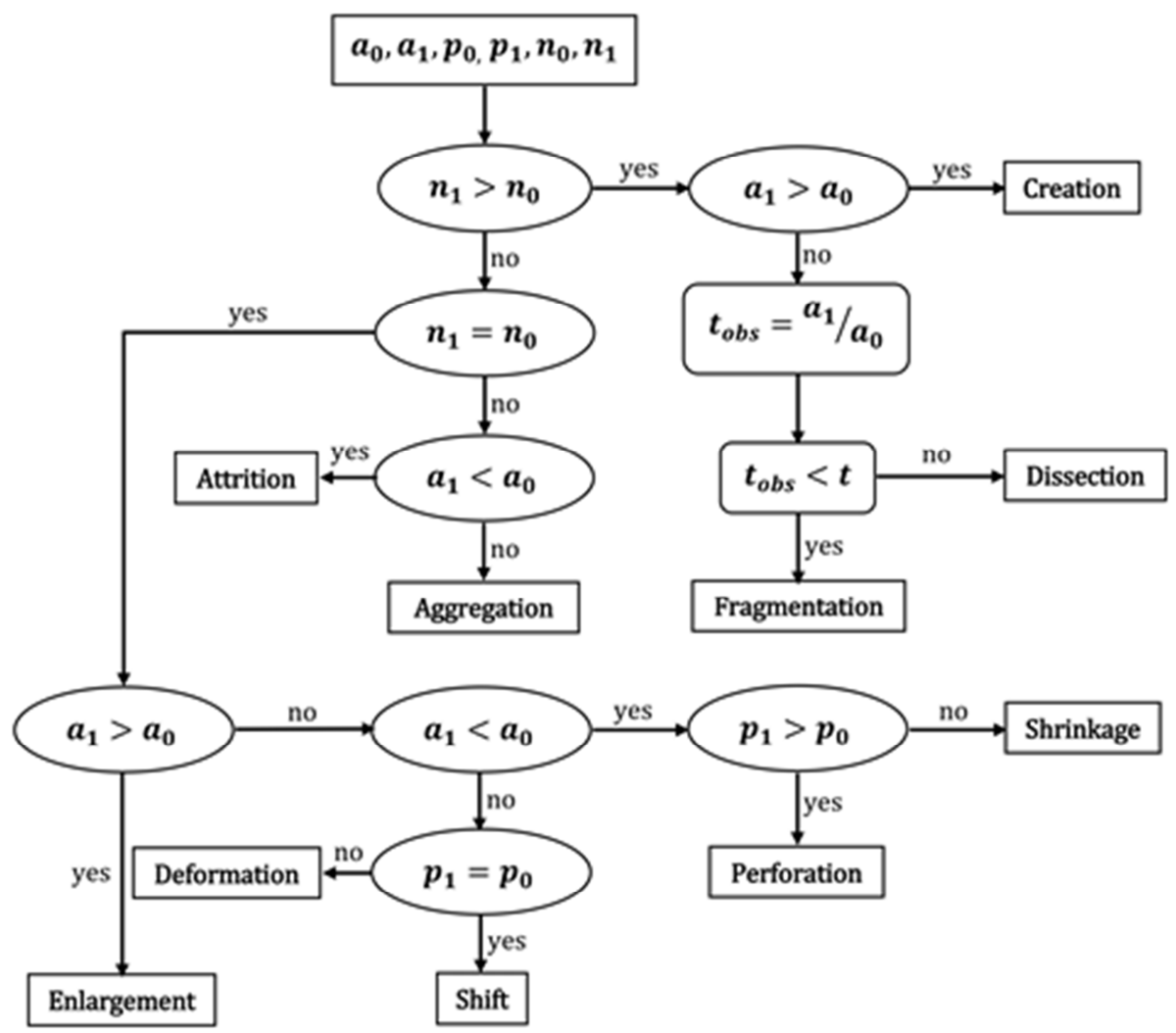

Figure 2. Decision tree for the Identification of the spatial transformation process. Model based on the decision tree of Bogaert [18]. $n_{0}$, $a_{0}, p_{0}$ and $n_{1}$, $a_{1}, p_{1}$ are respectively the number, area and perimeter of patches at dates $t_{0}$ and $t_{1}$. To separate the fragmentation and dissection processes, $t_{o b s}=a_{1} / a_{0}$ is calculated and compared to a predefined value $(t=0.5)$.

\section{Results}

\subsection{Land Cover Classes and Accuracy of Classifications}

Thanks to the field visit, three land use classes were synthesized in order to better observe the extent of the evolution of cashew tree crops in the landscape of the
Séguéla sub-prefecture. These classes included the Bare soil and agglomeration class, the Cashew nut class consisting solely of cashew nut plantations and the last one is the Noncashew nut class which includes forests, savannahs, water bodies, agricultural holdings other than cashew nut plantations. The confusion matrix of Landsat images indicates overall accuracies and Kappa coefficients of at least 
90\% (Table 2). These reliability evaluation indices reveal a supervised classifications. good discrimination of the classes defined during the

Table 2. Reliability of supervised classifications of the sub-prefecture Landsat images (2001, 2006, 2013 and 2018 ).

\begin{tabular}{|c|c|c|c|c|}
\hline & Class & Cash & N-Cash & BSAggl \\
\hline \multirow{4}{*}{2001} & Cash & 93.48 & 3.57 & 0.00 \\
\hline & N-Cash & 6.52 & 96.43 & 10.64 \\
\hline & BSAggl & 0.00 & 0.00 & 89.36 \\
\hline & Total & 100.00 & 100.00 & 100.00 \\
\hline \multicolumn{5}{|c|}{ Overall Accuracy: $93.29 \%$; Kappa Coefficient: 0.90} \\
\hline \multirow{3}{*}{2006} & Cash & 93.88 & 2.90 & 0.00 \\
\hline & N-Cash & 6.12 & 97.10 & 1.92 \\
\hline & Total & 100.00 & 100.00 & 100.00 \\
\hline \multicolumn{5}{|c|}{ Overall Accuracy: 97.47 \%; Kappa Coefficient: 0.95} \\
\hline \multirow{4}{*}{2013} & Cash & 98.59 & 0.00 & 0.00 \\
\hline & N-Cash & 1.41 & 100.00 & 4.11 \\
\hline & BSAggl & 0.00 & 0.00 & 95.89 \\
\hline & Total & 100.00 & 100.00 & 100.00 \\
\hline \multicolumn{5}{|c|}{ Overall Accuracy: $97.95 \%$; Kappa Coefficient: 0.98} \\
\hline \multirow{3}{*}{2018} & N-Cash & 2.94 & 100.00 & 1.23 \\
\hline & BSAggl & 0.00 & 0.00 & 98.77 \\
\hline & Total & 100.00 & 100.00 & 100.00 \\
\hline
\end{tabular}

Cash: Cashew; N-Cash: Non Cashew; BSAggl: Bare soil and Agglomeration.

The values in the diagonals indicate the percentage of pixels well classified at the occupancy class level and outside the diagonal of the confusion that exists between the classes.

\subsection{Description of the Composition and Structure of the Landscape}

After the process of validation of the supervised classification, land use maps were produced from satellite images (Figure 3). Throughout the study period (2001-2018), the non-Cashew class lost more than 6000 ha although it continued to be the dominant broad class in the landscape. Meanwhile, the area occupied by cashew nut plantations and the number of plantations continued to increase (Table 3). Indeed, cashew tree plantations were almost absent from the landscape of the Séguéla sub-prefecture in 2001 (0.07\% of the landscape of the entire sub-prefecture) with 83 plantations (Figure 4) spread over an area of 62.2 ha. In 2006, cashew tree plantations extended from north to southeast of the sub-prefecture with a number of plots passing from 83 to 304 . These plantations occupied a total area of 458.4 ha. In 2013, the number and area of cashew tree crops reached 978 plots and 2,871.73 ha. In 2018, the number of cashew nut plots rose to 1,290 plots spread over a total area of $4,678.5$ ha occupying $6.06 \%$ of the landscape.

Table 3. Number of patches (n), area (a) in Ha of the cashew nut class between 2001 and 2018 .

\begin{tabular}{lll}
\hline Years & Number of patch (n) & Area (a) \\
\hline 2001 & 83 & 62.2 \\
2006 & 304 & 458.4 \\
2013 & 978 & $2,871.73$ \\
2018 & 1290 & $4,678.5$ \\
\hline
\end{tabular}
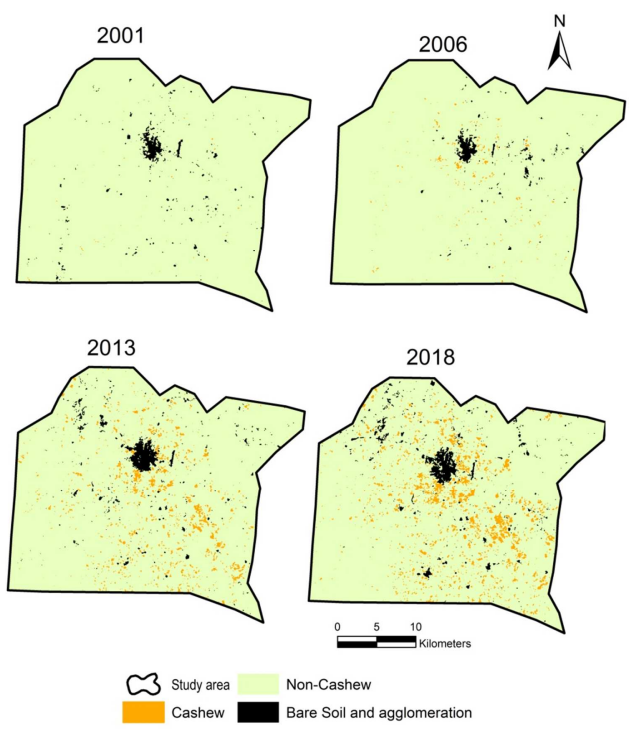

Figure 3. Land use maps showing the evolution of cashew nut cultivation in the Séguéla sub-prefecture from 2001 to 2018.

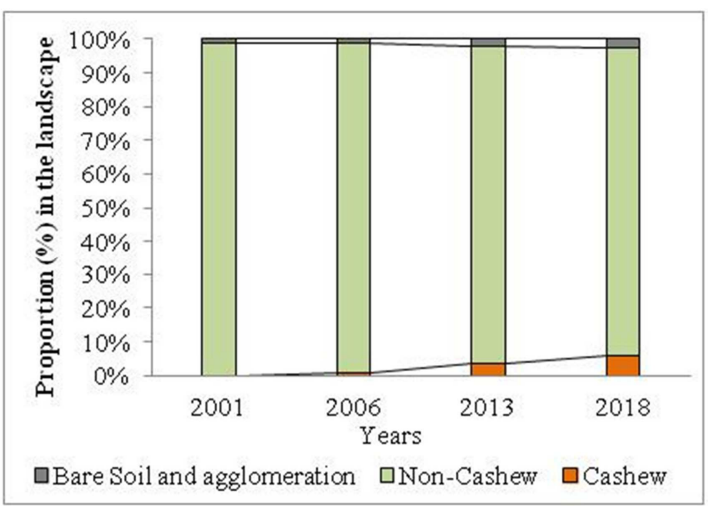

Figure 4. Proportion of land use classes in the landscape of the sub-prefecture. 


\subsection{Identification of Changes}

\subsubsection{Variation Trends in Land Use Units}

Land use classes have undergone changes in the three reporting periods: 2001/2006, 2006/2013 and 2013/2018 (Table 4). During the three periods, the cashew nut class experienced a growth rate with a strong trend. For example, a growth rate was $637.05 \%$ or $127.41 \%$ per year for the period 2001/2006. Meanwhile, the Non cashew class has a negative evolution until 2018 and the bare soil and agglomeration class, the initially negative rate of change between 2001 and 2006 reached positive values of more than $100 \%$ between 2006 and 2013 and then fell to $17.68 \%$ between 2013 and 2018 .

Table 4. Variation trends in land use types during the three periods defined between 2001 and 2018.

\begin{tabular}{|c|c|c|c|c|c|c|}
\hline \multirow{2}{*}{ Land cover type } & \multicolumn{3}{|c|}{ Difference (ha) } & \multicolumn{3}{|c|}{ Evolution rate $(\%)$} \\
\hline & $2001 / 2006$ & $2006 / 2013$ & 2013/2018 & $2001 / 2006$ & $2006 / 2013$ & $2013 / 2018$ \\
\hline Cashew & 396.2 & 2413.3 & 1806.77 & +637.05 & +525.66 & +63.14 \\
\hline Non cashew & -244.22 & -3360.18 & -2560.14 & -0.29 & -4.06 & -2.69 \\
\hline Bare soil and agglomeration & -160.01 & 951.63 & 328.44 & -14.42 & +104.18 & +17.68 \\
\hline
\end{tabular}

\subsubsection{Structure Dynamics and Spatial Transformation Processes of the Cashew Nut Class}

Over the years, the average area planted with cashew nuts has increased from 0.7 ha in 2001 to 3.6 ha in 2018 (Figure 5). In addition, the dominance of the largest cashew tree planting spot decreases as the years go by. Indeed, the value of the dominance of the largest spot increased from $7.24 \%$ in 2001 to $2.85 \%$ in 2018 (Figure 5). In addition, during the same period, the number of plots and the total area of cashew tree plantations increased in the landscape. Therefore, the spatial transformation process that has been reported for the cashew nut class is the creation of new cashew nut plantations.

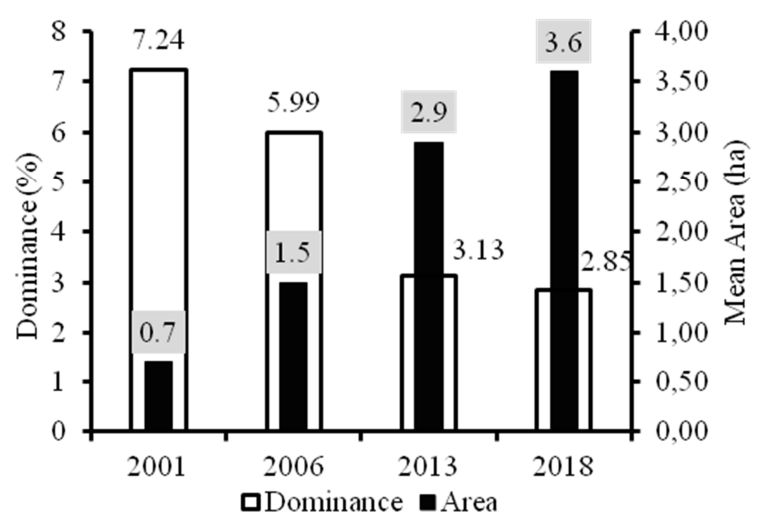

Figure 5. Dominance and average area of cashew tree planting between 2001 and 2018.

\section{Discussion}

\subsection{Mapping, Changing in Rural Landscape}

The production of land use maps highlighting cashew nut crops was a priority in this study. This has required satellite imagery from different dates. The advantage of using remote sensing in diachronic studies of land use dynamics is well established [19-20]. The maps resulting from satellite image processing that we used have very satisfactory mapping accuracy rates overall with Kappa values above 0.90 . This indicates that the images have been correctly classified, and the maps are acceptable. Indeed, according to references [21-
22], a Kappa score above 0.75 reflects a good classification score. The good cartographic accuracy is due to two factors. First, the mastery of the study area but also the choice of a reduced number of land use classes. Indeed, a solid knowledge of the field is an element that improves the quality of classification [23]. But also, many studies have shown that the fewer classes are, the more errors of confusion between them decrease [16, 20, 24]. The choice of only 3 classes is justified by the desire to better highlight cashew nut plantations and then study their expansion in this area of northern Côte d'Ivoire.

The dynamics observed from the land use maps show that between 2001 and 2018, the composition and structure of the landscape of the sub-prefecture of Seguela was significantly modified as a result of cashew nut cultivation. Then, almost non-existent in $2001(0.07 \%)$, cashew plantations are experiencing an increasingly large spatial hold. This progressive evolution of the total area of cashew tree plantations over the years has been accompanied by a continuous decrease in the dominance of the largest cashew tree planting patch and an increase in the average area of cashew tree plantations. This trend is due not only to the availability of land, but above all, to the increasingly attractive selling price of cashew nuts per kilogram. Consequently, according to [4, 25], attractive purchase prices have led to the expansion of this crop, which has become the main source of income for producers in the savannah regions of northern and central Côte d'Ivoire. In this region where the main activity remains agriculture, it has been shown that cashew nuts have increased the incomes of farmers and people and, above all, improved their living standards $[9,13]$. As a result of the guarantee of sales income and lower input costs, more and more farmers in West Africa continue engaging in cashew nut production as a cash crop [3].

\subsection{Impacts of Cashew Nut Expansion}

Considering the economic and social benefits associated with the production of cashew nuts, also called " brown gold " from the North, it is expected that the expansion trend will continue in the sub-prefecture of Seguela. However, the enthusiasm generated by this arboriculture must not lose sight of the changes in social relations within the population and the environmental impact of cultural practices [26]. In 
the sub-prefecture of Seguela, as in all of northern Côte d'Ivoire, there is an agrarian transformation where the cultivation of annual cotton is replaced by permanent cashew nut plantations [27-28]. Indeed, the cashew tree is a culture that has marked the space for about thirty years. This has both a positive and negative impact on the environment. On the one hand, cashew nut orchards limit soil erosion, promote regrowth and increase tree density in savannah landscapes [3, 29-31]. On the other hand, by affecting the dynamics of the rural landscape, this culture leads to a deterioration in the quality of carbon sequestration [6]. In addition, cashew proliferation leads to a reduction in biological diversity and the depletion of many local and vulnerable plant species [3233]. In terms of social relations, the monopolization of land for several decades has led to the emergence of new land conflicts already reported in some regions of Côte d'Ivoire between rural populations and between farmers and herders [8-9]. Some part, it said that the expansion of cashew farming is a way some farmers use to securing land, which is likely to become a big challenge in future [3]. In addition, the increase in cashew tree areas is detrimental to those of food crops associated with it in the first three years of cultivation [34]. Compared to cotton, the other cash crop in the area, with cashew nuts, the land does not return to set-aside. As a result, the replacement of food fields with cashew orchards year after year tends to move some of the food crops away from the villages. As a result, villages are gradually surrounding themselves with cashew trees and food crops are being planted "in the bush", generating a significant loss of working time. All this results in an increased risk of food insecurity in the medium term. This has already been observed in northeastern Côte d'Ivoire by [34].

\section{Conclusion}

Between 2001 and 2018, the composition and structure of the landscape of the Séguéla sub-prefecture were significantly modified by cashew nut cultivation. With satellite image treatment, this study showed that the dynamics of land use has been marked by a remarkable expansion of cashew nut cultivation. The process of creating new and larger parcels of land has been identified as the spatial transformation occurring in the cashew nut class. Indeed, almost non-existent in 2001 with only 83 plantations $(0.07 \%$ of the landscape), the number of orchards increased to 1290 in 2018. In addition, the total area of cashew nut plantations, which amounted to 62.2 ha in 2001 , increased by more than $7000 \%$ to $4,678.5$ ha in 2018 .

Cashew nut cultivation has now become one of the main cash crops in the savannah region of Côte d'Ivoire. Attractive purchase prices have enabled the expansion of this crop, which has become the main source of income for producers in the savannah regions of northern and central Côte d'Ivoire. Although it is recognized that cashews represent a hope for additional gains in financial income for the populations of this region. However, with rising land pressure, there is still time to develop mechanisms to avoid the environmental and social conflicts that this situation is already revealing in some regions of Côte d'Ivoire.

\section{Disclosure Statement}

The authors declare that they do not have any competing financial or professional interests from any other parties.

\section{References}

[1] Adeigbe, O. O; Olasupo, F. O.; Adewale, B. D.; Muyiwa A. A. (2015). A review of cashew research and production in Nigeria in the last four decades. Science Research Essays 10 (5), 196-209.

[2] Unnevehr, L. J.; Ronchi, L. (2014). Food Safety Standards: Economic and Market Impacts in Developing Countries. World Bank Group: Washington, DC, USA.

[3] Monteiro, F, Catarino L., Batista D., Indjai B., Duarte M. C. and Romeiras M. M. (2017). Cashew as a High Agricultural Commodity in West Africa: Insights towards Sustainable Production in Guinea-Bissau. Sustainability, 9, 1666; doi:10.3390/su9091666.

[4] Nugawela, P.; Balde, A.; Poublanc, C. (2006). La chaîne de valeurs anacarde au Sénégal, analyse et cadre stratégique d'initiatives pour la croissance de la filière. Programme USAID/ croissance économique, $78 \mathrm{p}$.

[5] Ollenburger, M. H.; Descheemaeker, K.; Crane, T. A.; Sanogo, O. M.; Giller, K. E. (2016). Waking the Sleeping Giant: Agricultural intensification, extensification or stagnation in Mali's Guinea Savannah. Agricultural Systems 148, 58-70.

[6] Laurance, W. F.; Sayer, J.; Cassman, K. G. (2014). Agricultural expansion and its impacts on tropical nature. Trends Ecological Evolution, 29, 107-116.

[7] Zhang Y., Li Y., Jiang L., Tian C., Li J., and Xiao Z. (2011). Potential of Perennial Crop on Environmental Sustainability of Agriculture. Procedia Environmental Sciences 10, 1141 1147.

[8] Konan, K. H.; Diomande, G.; Kra, K. J. (2016). Cashew nut cultivation and the new game of actors in the conflict between farmers and herders in the Sohouo sub-prefecture in northern Côte d'Ivoire. Journal Of Humanities And Social Science, 21 (11), 24-32.

[9] Adaman, S.; N'Dri, K. A. (2016). Socio-economic impact of cashew nut cultivation in the Odienne sub-prefecture (Côte d'Ivoire). European scientific journal, 12 (32), 369-384.

[10] Richard, J. (1972). The forest-savannah contact in the CentreWest of Cote d'Ivoire (Seguela- Vavoua): aspects and meanings. ORSTOM, Abidjan, Côte d'Ivoire, $172 \mathrm{p}$.

[11] Gauthier, M.; Delpiano, P.; Erwin-field; Petit G. (2015). The Odienné-Séguéla region. Volume 1. Socio-economic analysis. Edition CEGOS, Puteaux (France), 257 p.

[12] Koffi, Y. J. (2012). The dynamics of cashew nut processing in rural areas of Central and Northern Côte d'Ivoire. Revue de géographie du laboratoire Leïdi, 2515 (10): 179-199.

[13] Ricau, P. (2013). Knowing and understanding the international cashew nut market. RONGEAD, 49p. 
[14] Hogland J., Billor N.; Anderson N. (2013) Comparison of standard maximum likelihood classification and polytomous logistic regression used in remote sensing. European Journal of Remote Sensing, 46:1, 623-640, DOI: $10.5721 / \mathrm{EuJRS} 20134637$.

[15] Abdel-Kawy, O. R.; Rod, J. K; Ismail, H. A.; Suliman, A. S. (2011). Land use and land cover change detection in the western Nile delta of Egypt using remote sensing data. Applied Geography, 31 (2): 483-494.

[16] Mama, A.; Bamba, I.; Sinsin, B.; Bogaert, J.; De Cannière, C. (2014). Deforestation, transformation into savannah and agricultural development in the savannah and forest landscapes of Benin's sudano-guinean zone. Bois et forêts des tropiques, 322 (4), 65-76.

[17] Bamba, I.; Mama, A.; Neuba, D. F. R.; Koffi, K. J.; Traore, D.; Visser, M.; Sinsin, B.; Lejoly, J.; Bogaert, J. (2008). Influence of anthropogenic actions on the spatio-temporal dynamics of land cover in the Central Congo province (Congo D. R). Sciences \& Nature, 5, 49-60.

[18] Bogaert, J.; Ceulemans, R.; Salvador-Van, E. D. (2004). Decision tree algorithm for detection of spatial processes in landscape transformation. Environmental Management, 33, 62-73.

[19] Oszwald, J.; Atta, J. M. K.; Kergomard, C.; Robin, M. (2007). Portray space to structure time: approach of the forest change dynamics in south-eastern Côte d'Ivoire by remote sensing. Télédétection, 7(1-2-3-4), 271-282.

[20] Barima, Y. S. S.; Kouakou, A. T. M.; Bamba, I.; Sangne, Y. C.; Godron, M.; Andrieu, J.; Bogaert, J. (2016). Cocoa crops are destroying the forest reserves of the classified forest of Haut-Sassandra (Ivory Coast). Global Ecology and Conservation, 8, 85-98.

[21] Streiner, D. L.; Norman, G. R. (1989). Health Measurement Scales: A Practical Guide to their Development and Use. Oxford University Press, UK.

[22] Montserud, R. A.; Leamans, R. (1992). Comparing global vegetation maps with the Kappa statistic. Ecological Modelling, 62(4): 275-293.

[23] Toyi, M. S. S.; Eda, A. F.; Barima, Y. S. S.; Bamba, I.; Sinsin, B. (2018). Landscape dynamics of the Lama Classified Forest in southern Benin, Tropicultura, 36 (2): 217 - 231.

[24] Caloz, R.; Collet, C. (2001). Précis de télédétection. Volume 3: Digital processing of remote sensing images (French- speaking universities)). Québec, Canada, Presses Polytechniques du Québec, 368 p.

[25] Lebaily, P.; Lynn, S.; Seri, H. (2012). Study for the preparation of a strategy for the development of the cashew nut sector in Côte d'Ivoire. Diagnostic Report. AGRER Consortium, 92 p.

[26] Le Guen, T. (2004). Agricultural and pastoral development in northern Côte d'Ivoire: issues in coexistence. Les Cahiers d'Outre-Mer [Online], 226-227 consulted on November 05 2018. URL: http://journals.openedition.org/com/563; DOI: 10.4000/com.563.

[27] Kambire, B. (2012). The Bouna region challenged by its demarginalization for 50 years. In Koffi-Bipko Y.-C. (dir.), Côte d'Ivoire, 50 years of independence: permanence, mutation and/or evolution of territories. L'harmattan, p. 221248.

[28] Sokemawu, K. (2015). Development of the cashew nut sector in the prefecture of Tchamba in Togo: towards a new peasant strategy for diversifying agricultural incomes. Revue de Géographie de l'Université de Ouagadougou, 4 (2), 21-42.

[29] Dugué P.; Koné, F. R.; Koné, G. Management of natural resources and development of agricultural production systems in the savannah of Côte d'Ivoire: implications for agricultural policy development. Cahiers Agricultures, 12(4), 267-273.

[30] Dugué, P.; Koné, F. R., Koné, G.; Akindes, F. (2004). Agricultural production and livestock in the central cotton basin of Côte d'Ivoire. Cahiers Agricultures, 13(6), 504-509.

[31] Yabi, A. J.; Tovignan S. D.; Moustafa R. (2013). Analysis of maize production and supply for food security improvement in the Borgou region in Northeast of Benin. African Journal of Agricultural Research, 8 (11): 943-951.

[32] Aké Assi, L. (1998). The impact of forestry and agricultural development on the conservation of biological biodiversity in Côte d'Ivoire. Le flamboyant 46, 20-21.

[33] Koulibaly, A.; Akédrin, N.; Massé, D.; Konaté, I.; Traoré, D.; Ralf, B.; Kouadio, Y. J. (2016). Consequences of cashew tree cultivation (Anacardium occidentale L.) on vegetation characteristics in the Comoé National Park area (Côte d'Ivoire). International Journal of Innovation and Applied Studies, 17 (4), 1416-1426.

[34] Kouakou Kouamé, A.; Adaye, A. K.; Koffié-Bikpo, C. Y. (2017). Impact of cashew nut cultivation on the food security in Bondoukou department. Revue de Géographie Tropicale et d'Environnement, 2, 7-16. 